\title{
ЭТНОЭКОЛОГИЧЕСКОЕ ОБРАЗОВАНИЕ БУДУЩИХ ПЕДАГОГОВ
}

\author{
Григорьева Л.И. ${ }^{1}$, Сакердонова А.С. ${ }^{1}$ \\ ФГАОУ ВО «Северо-Восточный федеральный университет имени М. К. Аммосова», Якутск, е-таіl: lиbоv- \\ grigor2011@mail.ru, asakerdonova2004@mail.ru
}

\begin{abstract}
Актуальность темы исследования заключается в глобальной угрозе наступающего мирового экологического кризиса, обусловленной потребительским отношением человечества к окружающей природе, разрушением гармоничного сосуществования и взаимодействия. Необходим поиск путей, направленных на предотвращение надвигающейся масштабной экологической катастрофы. Данное положение определяет необходимость введения в образовательный процесс вопроса воспитания подрастающего поколения, обладающего экологической культурой, основанной на этнокультурных знаниях. Необходимость определения педагогических условий этноэкологического образования студентов педагогических вузов становится актуальной задачей высшего образования. Цель исследовательской работы - раскрытие содержания этноэкологической направленности педагогического образования подготовки бакалавров по профилю «Начальное образование». В ходе исследовательской работы была определена сущность понятия «этноэкологическое образование», выявлен достаточный уровень содержания дисциплин по этноэкологической направленности при подготовке бакалавров по профилю «Начальное образование» и раскрыты педагогические условия формирования этноэкологической культуры студентов. Специфика темы исследования придает научной работе уникальность, ценность которой заключается в идее раскрытия проблемы содержания этноэкологического образования в высшей школе. В перспективе исследования по данной теме намечается дальнейшая работа по совершенствованию этноэкологического образования будущих педагогов по профилю «Начальное образование».

Ключевые слова: этноэкология, этноэкологическое образование, экологическая культура, этноэкологическая культура, учитель начальных классов, младший школьник
\end{abstract}

\section{ETHNO-ECOLOGICAL FORMATION OF FUTURE TEACHERS}

\author{
Grigorieva L.I. ${ }^{1}$, Sakerdonova A.S. ${ }^{1}$ \\ ${ }^{1}$ North-Eastern Federal University,NEFU, Yakutsk, e-mail: lubov-grigor2011@mail.ru, asakerdonova2004@mail.ru
}

Annotation. The relevance of the research topic lies in the global threat of the coming global environmental crisis caused by the consumer attitude of mankind to the surrounding nature, the destruction of harmonious coexistence and interaction. It is necessary to find ways to prevent the impending large-scale environmental disaster. This provision determines the need for introducing into the educational process the issue of educating the younger generation with an ecological culture based on ethnocultural knowledge. The need to determine the pedagogical conditions of ethno-ecological education of students of pedagogical universities is becoming an urgent task of higher education. The purpose of the research work is the disclosure of the ethno-ecological orientation of pedagogical education and the preparation of bachelors in the "Primary Education" profile. In the course of the research, the essence of the notion "ethno-ecological education" was determined, a sufficient level of content of disciplines on ethno-ecological orientation for the preparation of bachelors in primary education was revealed, and the pedagogical conditions for the formation of students' ethno-ecological culture were revealed. The specificity of the research topic gives scientific work its uniqueness, the value of which lies in the idea of disclosing the problem of the content of ethno-ecological education in higher education. In the future, research on this topic outlines further work to improve the ethno-ecological education of future teachers on the primary education profile.

Keywords: ethno-ecology, ethno-ecological education, ecological culture, ethno-ecological culture, primary school teacher, younger student

Важнейшая задача человечества в XXI в. представляется как необходимость сохранения окружающей среды посредством формирования экологической культуры общества. Особую актуальность приобретает проблема взаимодействия природы и человечества в современном индустриальном мире, в мире искусственных ценностей технического прогресса общества. Превращение природы в источник потребления 
человечества, ее обезличение привело к разрушению экологического баланса в окружающем мире. В результате этого современное общество получило несколько поколений людей с потребительским отношением к окружающей природе, что привело к разрушению природного равновесия. Необходим поиск путей, направленных на предотвращение надвигающейся масштабной экологической катастрофы. Как показывают многочисленные исследования по данной проблеме, одним из действенных механизмов решения проблемы является изменение ориентации человечества от технократических ценностей к экологически ориентированным ценностям. Для этого необходимы изменение мышления, формирование экологической культуры у подрастающего поколения на основе этнокультурных знаний.

Проблему экологического образования подрастающего поколения в педагогической науке рассматривал еще Я.А. Коменский, она была обоснована в его известном принципе природосообразности. Данный принцип также обоснован в трудах великих педагогов Ж.Ж. Руссо, И.Г. Песталоцци, А.В. Дистерверга и других его последователей. Принцип природосообразности понимался и трактовался разносторонне, но суть его заключалась в том, что гармоничное развитие личности подчинено и подобно процессам природы. В настоящее время можно утверждать, что развитие личности непосредственно зависит от воздействия окружающей природы, которая в свою очередь зависит от человеческого воздействия на нее. Таким образом, можно подчеркнуть ценность природы в образовании и воспитании ребенка как педагогического средства воздействия на развитие гармоничной личности, что в своих трудах отмечали также наши отечественные педагоги К.Д. Ушинский и В.А. Сухомлинский.

Педагогические идеи великих педагогов прошлого о воспитании средствами природы стали основой развития современных теорий экологического образования. Теоретикометодологическая основа экологического образования разработана в трудах И.Д. Зверева, А.Н. Захлебного, Н.Ф. Виноградовой, Т.А. Куликовой и др. Вопросы формирования экологически культурной личности исследованы такими учеными, как Е.В. Асафова, Т.А. Козлова, Б.Г. Иоганзен и др. Взаимодействие этноса с окружающей природой рассматривается в трудах П.С. Гуревича, Л.Н. Гумилева, В.Г. Красько, М.С. Каган и др. Этнический подход в экологическом образовании и воспитании раскрыт в исследованиях Л.И. Григорьевой, А. Халимова, М.В. Емельяновой.

Недостаточная разработанность проблемы этноэкологического образования подрастающего поколения подтверждает актуальность темы исследования. Важность подготовки будущих педагогов к этноэкологическому образованию детей, формирования у студентов экологического сознания, ценностного отношения к окружающей среде, основанной на этнокультурных знаниях, обусловила выбор темы исследования. 
Целью исследования является раскрытие содержания этноэкологической направленности педагогического образования подготовки бакалавров по профилю «Начальное образование».

Материал и методы исследования. Исследование представляет собой обобщение опыта работы кафедры начального образования Педагогического института СевероВосточного федерального университета им. М.К. Аммосова. В ходе исследовательской работы решались следующие задачи: определить сущность и степень разработанности понимания понятия «этноэкологическое образование»; раскрыть этноэкологическую направленность содержания дисциплин программы подготовки бакалавров по профилю «Начальное образование»; выявить педагогические условия формирования этноэкологической культуры студентов. Для решения поставленных задач в процессе исследовательской работы были применены следующие методы: теоретический анализ научной литературы по теме исследования, метод прикладного исследования.

Результаты исследования и их обсуждение. Этническая экология как научная дисциплина стала складываться относительно недавно, в середине XX в., и связана с исследованиями этноэкологических аспектов в трудах В.П. Алексеева, С.А. Арутюнова, В.И. Козлова и др. Впервые определение этнической экологии как научного направления дал В.И. Козлов, считая этническую экологию «неразрывно связанной с этнографией (этнологией), этническая экология ставит в центр своего внимания, в качестве объекта исследования, этносы как естественно-исторически возникшие, устойчивые общности людей, обладающие специфической культурой и бытовыми традициями, которые проявляются в процессах адаптации и жизнеобеспечения различных групп людей» [1, с. 20]. Этнограф отмечает, что «в основные “предметные” задачи этнической экологии входит изучение особенностей традиционных систем жизнеобеспечения (в самом полном значении этого термина) этнических групп в природных и социально-культурных условиях их обитания, а также влияние сложившихся этноэкологических взаимосвязей на здоровье людей и процессы естественного воспроизводства в этнических группах, изучение культурной специфики использования этническими группами природной среды и специфики их воздействия на эту среду, определение закономерностей формирования и функционирования относительно независимых этноэкологических систем» [1, с. 21].

Этнические общности народов Севера - это уникальный исторически сложившийся в суровых природно-климатических условиях социум. Эти народы с различными этнокультурными особенностями языка, обычаями, традициями при взаимодействии друг с другом имеют одно общее - ценностное отношение к природе. Этнопедагогические 
воззрения народов Севера определяют этнографические, фольклорные материалы, раскрывающие экологическую направленность воспитания подрастающего поколения.

Таким образом, природно-климатические факторы формируют особенную этноэкологическую культуру, традиции и характер взаимоотношения в системе «человек и природа». Понятие «этноэкологическая культура» раскрывает этнический код, определяющий устойчивые формы и способы человеческого взаимоотношения с окружающей природной средой, выраженные в поведении человека, основанном на этноэкологических знаниях. В дальнейшем попытаемся раскрыть понятие «этноэкологическое образование» через понятие «экологическое образование».

Существуют различные определения понятия «экологическое образование». Так, к примеру, в Национальной педагогической энциклопедии понятие «экологическое образование» определяется как «система знаний об окружающем мире как среде жизнедеятельности человека, о влиянии производственной деятельности на природную среду, а также знания и навыки природоохранительной деятельности» [2].

В Педагогическом словаре «экологическое образование как элемент общего образования связано с овладением учащимися научными основами взаимодействия природы и общества. Его цель - формирование системы знаний, взглядов и убеждений, направленных на воспитание моральной ответственности личности за состояние окружающей среды, осознание необходимости постоянной заботы о ней во всех видах деятельности» [3].

Исходя из вышеизложенного сущность понятия «этноэкологическое образование» можно представить как целенаправленно организованный, планомерно и систематически осуществляемый процесс привития экологических знаний обучающимся, формирование ценностного отношения к природе, овладение способами природоохранительной деятельности, основанными на этноэкологических знаниях и этнокультурных традициях в системе «человек и природа».

Очевидно, воспитание детей у народов Севера имело характер экоориентированной направленности, основанной на этноэкологических знаниях. Испокон веков у народов Севера воспитание личности, способной выжить в суровых климатических условиях в гармонии с окружающей природой, было основным фактором жизнеспособности этносов. Знание этноэкологических традиций обеспечивало равновесие в соразвитии этносов и окружающей природы. Ведь опыт ведения традиционного хозяйствования, знания об особенностях окружающей среды, освоении новых территорий у народов Севера передавались из поколения в поколение в течение многих веков. У каждого поколения на основе привитых этноэкологических знаний предков вырабатывались определенные взаимоотношения и этнокультурные установки с природой и окружающим миром в целом. 
В настоящее время в силу глобализации и индустриализации современного общества наблюдается тенденция утери этноэкологических знаний и традиций молодым поколением. Г.Ц. Цыбекмитова считает, что необходимо введение в образовательный процесс вопроса воспитания подрастающего поколения, обладающего экологической культурой, знаниями этнического природопользования [4]. Как утверждает ученый: «Этот богатый материал, основанный на знании практики взаимоотношения этносов с природной средой, богатство духовного и материального мира, дает возможность ориентации экологического образования на освоение этнического опыта природопользования, отражающего этноэкологические идеи о сотворчестве человека и природы, вписанности человека в целостную систему» [4].

Исследователи этнокультурных традиций отмечают, что у этносов, проживающих на Севере, наблюдается особое чувственное отношение к природе. Они выделяют существование парадигмы экологического сознания как результат жизнедеятельности этносов в экстремальных природных условиях Севера. А.А. Сирина [5] выделяет «экологическую этику» у этносов, населяющих Север, основанную на исторически сложившейся устойчивой традиции бережного отношения к природе. К примеру, у народов Севера запрещалось шуметь, находясь на природе, так как по этническим представлениям объекты природы одушевлялись, природа представлялась как нечто живое. Каждый объект природы имел духа-хозяина, к которому надо было относиться с глубоким уважением и благодарностью. Принцип бережного отношения к природе глубоко отражается в фольклоре народов Севера, что определяет их экологическую культуру.

Таким образом, можно предположить, что сущность этноэкологического образования заключается в формировании экологически культурной личности, личности с развитым этническим самосознанием, понимающей сущность органичного взаимодействия в системе «человек и природа». Становление личности с этноэкологическим сознанием должно быть основано на нормах и нравственных принципах бережного отношения к природе, на этнической культуре природопользования, на этноэкологических знаниях предков и этнокультурных установках гармоничного сосуществования с окружающей природой.

Рассмотрим возможности учебных дисциплин, включенных в ООП профиля бакалавриата «Начальное образование», в осуществлении этноэкологического образования будущих учителей начальных классов школ Севера. Основную роль по данному направлению призваны выполнять учебные дисциплины естественнонаучного цикла.

Дисциплины, обладающие содержательным, мировоззренческим и познавательным потенциалом, имеют немаловажное значение для формирования ключевых компетенций в ходе реализации компетентностного подхода. Естественные науки являются фундаментальными, способствующими интеллектуальному развитию, формированию 
научного миропонимания, объективному познанию законов мира. Как отмечает Н.М. Кокшарова, «одной из предпосылок формирования ключевых компетенций будущего специалиста в условиях естественнонаучного образования является возможность развития у студентов целостного представления о научной картине мира как неотъемлемой части общей культуры современного человека» [6, с. 35].

Как показывает анализ ООП по профилю «Начальное образование», естественнонаучный цикл включает следующие дисциплины: «Естествознание», «Экологическое воспитание младших школьников», «Методика преподавания интегративного курса “Окружающий мир”».

Необходимо отметить, что дидактические цели эколого-образовательной и экологовоспитательной направленности подготовки будущих специалистов опираются на ряд наук, являющихся основой для вышеперечисленных дисциплин. Экологическая культура опирается на знания научной картины мира, изучение дисциплины «Естествознание» входит в общекультурный модуль. Предполагается, что изучение дисциплины «Естествознание» дает представление о мире как о едином целом, формирует у студентов совокупность взглядов и принципов видения мира, понимание экосистемы Земли как достояния, которое надо беречь. Педагогические основы экологического образования предполагают, что методы и формы организации учебной работы по дисциплине «Естествознание» способствуют качественной профессиональной готовности студентов.

При освоении дисциплины «Экология Якутии», «Методика преподавания интегративного курса “Окружающий мир”» будущие педагоги изучают современное состояние экологии Республики Саха (Якутия). Содержание дисциплины сформировано на основе экологической ситуации на территории республики и охватывает такие темы, как:

- экологические проблемы республики Саха (Якутия);

- формирование экологической культуры школьников;

- традиции народов Севера как образец бережного отношения к природе;

- хрупкость северных экосистем и др.

Будущий учитель начальных классов должен знать не только принципы охраны природы, науку экологию в целом, но и особенности экологического состояния региона. Экологическая культура будущих педагогов основывается на знании этнической культуры народов Севера, их готовности к организации экологического образования младших школьников с учетом природной специфики региона.

Программой учебной дисциплины «Экологическое воспитание младших школьников» предусматривается овладение студентами знаниями о современных методиках экологического воспитания младших школьников на основе знаний традиционного 
природопользования, экологической культуры народов Севера и применения этих знаний в будущей профессиональной деятельности. Исходя из этого можно предположить, что в подготовке учителей для школ Севера важной задачей является формирование их этноэкологической культуры.

Освоение дисциплины «Методика преподавания интегративного курса «Окружающий мир» наряду с общепедагогическими, методическими знаниями предполагает формирование у студентов экологических и краеведческих знаний.

К каждым естественнонаучным дисциплинам разработаны пособия для самостоятельной работы студентов: «Учебно-полевая практика по естествознанию», «Самостоятельная работа студентов по дисциплине “Естествознание: Зоология и Краеведение"». Изложены краеведческие материалы для изучения интегративного курса «Окружающий мир» в начальной школе, использованы уникальные источники по экологии растений и животных. Студент может получить дополнительную информацию, проработать во внеурочное время учебные и научные тексты, составить доклады, проекты, сделать обзор семейств растений и классов животных, может самостоятельно работать с материалами пособий в системе Moodle. Важно отметить, что в содержание всех дисциплин естественнонаучного цикла включены разделы, раскрывающие экологические особенности региона.

Таким образом, преподавание этноэкологических основ природопользования с учетом специфики региона в курсе данных дисциплин направлено на формирование экологического образа мышления и опирается:

- на эколого-педагогический опыт коренных народов Республики Саха (Якутия) в системе экологического образования;

- на новейшие факты состояния окружающей среды;

- на данные природоохранительной деятельности различных экологических организаций.

Основной задачей учебно-воспитательного процесса в вузе является формирование у студентов ценностей, потребностей и мотивов, составляющих основу профессиональной культуры. Личность студента формируется и развивается не только в условиях учебного процесса, но и во внеучебной деятельности. Воспитательная работа во внеаудиторное время может являться эффективным способом подготовки компетентных специалистов.

Этноэкологическое образование студентов Педагогического института осуществляется и во внеурочное время. Согласимся с утверждением Афониной, что «практическая реализация образовательного процесса по естественнонаучным дисциплинам, реализуемым в условиях компетентностной образовательной модели в гуманитарном вузе, требует решения задач, связанных с согласованием основных компонентов педагогической 
системы “цель - содержание - средства - результат”, разработкой педагогических средств организации субъект-субъектных взаимоотношений участников педагогического процесса, самостоятельной и творческой учебной деятельности, профессионально-личностной и общекультурной направленности содержания образования» [7, с. 8]. Профессиональная подготовка будущих учителей школ Севера в экологическом и этнокультурном направлении обеспечивается их практическим участием в мероприятиях по данным направлениям. «Если создана модель экологической образовательно-воспитательной среды, то можно добиться у обучающихся ответственного отношения к природной среде. Но для этого необходимы следующие условия: социально-педагогические и естественно-природные. Модель предусматривает не только передачу знаний, но и пробуждение эмоционально-чувственного компонента сознания. Иначе говоря, социально-педагогический и природный факторы рассматриваются в единстве» $[8$, с. 71$]$.

На кафедре начального образования Педагогического института функционируют студенческие кружки экологического и этнокультурного направления, члены которых активные участники научно-практических конференций, различных мероприятий этноэкологического характера, способствующих развитию творческой и общественной активности студентов. К примеру, с 2015 г. кружковцы участвуют во Всероссийском географическом диктанте. Географический диктант не только способствует грамотности, но и приобщает молодого человека к географии родной страны, а будущим учителям помогает приобрести компетентность, которая поможет при изучении интегративного курса «Окружающий мир».

Установлено, что патриотическая культура человека начинается с любви к родному краю - природе, людям, культуре, к своему дому. Патриотическое и экологическое воспитание молодежи имеет разносторонний характер: это Интернет - олимпиада по экологии, участие в экологических акциях «Личный пример», «Чистый город», «День Земли».

В формировании этноэкологической культуры немаловажную роль играет внеаудиторная деятельность студентов. Участие студентов в различных мероприятиях экологической и этнокультурной направленности способствует формированию ценностей и мотивов, необходимых для развития адекватного поведения в окружающей природной среде. Ежегодно студенты кафедры начального образования участвуют в республиканской научнопрактической игре «Отходы в доходы» с разными проектами, в исследовательской работе: в конкурсе плакатов, фотографий, «Экомода», «Флешмоб».

Можно предположить, что внеаудиторная работа студента, являясь компонентом учебно-воспитательного процесса: 
- развивает творческие и индивидуальные способности студентов;

- вовлекает студентов в эколого-педагогическую деятельность;

- раскрывает интересы к краеведению, к этнокультуре народов Севера, склонности студентов к природосберегательной деятельности.

Очевидно, что формирование этноэкологической культуры будущих педагогов носит системный характер и заключается в комплексном подходе к организации учебновоспитательной работы, в единстве учебного и внеучебного процессов. Системность и единство всего образовательного процесса создают благоприятные условия для формирования у студентов экологической и этнической культуры.

Выводы. Мы предполагаем, что этноэкологическому образованию студентов, обучающихся по профилю бакалавриата «Начальное образование», способствует ряд педагогических условий:

- содержание дисциплин естественнонаучного цикла направлено на формирование экологического мышления, опирающегося на этнокультурный опыт природоохранительной деятельности коренных народов Республики Саха (Якутия);

- активизация внеучебной деятельности студентов в экологическом и этнокультурном направлении обеспечивается их практическим участием в мероприятиях по данным направлениям;

- систематизация этноэкологического образования студентов осуществляется через комплексный подход организации учебно-воспитательной работы, посредством единства учебной и внеаудиторной деятельности.

Как показывает анализ содержания этноэкологической направленности педагогического образования подготовки бакалавров по профилю «Начальное образование», необходима разработка методических рекомендаций по педагогическому сопровождению этноэкологического образования студентов, методического пособия поэтапной реализации педагогических методов, средств и технологий с целью формирования и развития этноэкологической культуры будущих педагогов.

Профессиональная подготовка студентов педагогического института требует внедрения в содержание высшего образования этноэкологически направленных дисциплин, отражающих формирование знаний, умений и навыков в области этнической экологии. В понятие «этноэкологическое образование студентов» мы вкладываем экологизацию учебновоспитательного процесса на основе этнокультуры коренных народов. Таким образом, этноэкологическое образование будущих учителей реализуется через дисциплины естественнонаучного цикла, которые содержат этноэкологические основы 
природопользования. Этнокультурное образование студентов должно носить системный и комплексный характер, определяющийся в единстве всего образовательного процесса.

\section{Список литературы}

1. Этноэкологические аспекты духовной культуры / Ред. В.И. Козлов, А.Н. Ямсков, Н.И. Григулевич, М.: ИЭА РАН, 2005. 324 с.

2. Национальная педагогическая энциклопедия [Электронный pecypc]. URL: http://didacts.ru/termin/ekologicheskoe-obrazovanie.html (дата обращения: 01.10.2018).

3. Педагогический энциклопедический словарь / гл. ред. Б.М. Бим-Бад. М.: Большая Рос. энцикл., 2002. 527 с.

4. Ц Цыбекмитова Г.Ц. Воспитательный потенциал этноэкологических знаний и их роль в формировании экологической культуры студентов // Сибирский педагогический журнал. 2008. № 12. С. 184-194.

5. Сирина А.А. Чувствующие землю: экологическая этика эвенков и эвенов // II Этнограф. обозр. 2008. № 2. С.121-138.

6. Кокшарова Н.M. Дисциплины естественнонаучного цикла в контексте компетентностного подхода // Вестник НовГУ. 2009. № 53. С. 35-36.

7. Афонина Р.Н. Основные аспекты совершенствования естественнонаучного образования в гуманитарном вузе // Здоровье и образование в XXI веке. 2017. Том 19 (10). С. 3-9. URL: https://e-pubmed.co.uk/gallery/2017e-19-10-3-9.pdf (дата обращения: 24.10.2018).

8. Саввинов А.С., Григорьева Л.И. Природа как активный фактор, формирующий экологическое сознание обучаемого // Вестник Северо-Восточного федерального университета имени М.К. Аммосова. 2016. №3 (03). С. 67-73. 